\title{
Patients' return-to-work expectancy relates to their beliefs about their physician's opinion regarding return to work volition and ability
}

This article was published in the following Dove Medical Press journal: Journal of Pain Research

\author{
Benjamin Claréus' \\ Emma A Renström² \\ 'Department of Psychology, \\ Lund University, Lund, Sweden; \\ ${ }^{2}$ Department of Psychology, \\ Gothenburg University, Gothenburg, \\ Sweden
}

Purpose: This study investigates the relationship between sick-listed patients' return to work (RTW) expectancy and how they perceive that their physicians evaluate their ability and volition for RTW.

Methods: Hierarchical logistic regression controlling for sociodemographic factors and pain characteristics was carried out on cross-sectional data from 205 participants (mean age= $47.24 \pm 9.66$ years, $83.9 \%$ women). They were currently on full-time sick leave with a total duration of 10 years or less and represented various diagnosed and undiagnosed pain conditions.

Results: A positive expectation for RTW within a year was significantly associated with the belief that the physician favorably evaluated one's ability $(\mathrm{OR}=1.44,95 \% \mathrm{CI}=1.13-1.83)$ and volition $(\mathrm{OR}=1.42,95 \% \mathrm{CI}=1.11-1.83)$ to $\mathrm{RTW}$. This held even when other variables significantly associated with RTW expectancy were accounted for. Beyond beliefs, only age made a significant contribution in our final model $(\mathrm{OR}=0.94,95 \% \mathrm{CI}=0.90-0.98)$.

Conclusion: The results indicate that patients' beliefs regarding their physician's opinion about their ability and volition for RTW influence their own RTW expectancy. Rehabilitation might be facilitated if health care professionals address and affirm patients' ability and volition for RTW, regardless of patients' pain characteristics or if the total duration of their sick leave is $<10$ years. As other studies have found that RTW expectancy is one of the strongest predictors for actual RTW, future research should test the effect of beliefs about physicians' opinions on actual RTW rates.

Keywords: rehabilitation, pain, outcome expectations, general practice, RTW

\section{Introduction}

Expectation can be defined as the anticipation of a certain outcome resulting from previous experiences ${ }^{1}$ and has recently gained an increasing amount of attention in rehabilitation research. A positive expectation of recovery, eg, return to work (RTW), is closely associated with attitudes about one's ability (ie, "can do") and volition (ie, "want to do") to recover. ${ }^{2-6}$ Expecting to RTW is suggested to facilitate attitudinal and behavioral changes that increase the likelihood of future RTW. ${ }^{5}$ Accordingly, several studies have demonstrated that a positive expectancy of RTW is associated with actual RTW in individuals sick-listed due to pain. ${ }^{7,8}$ Positive RTW expectancy also predicts quicker RTW ${ }^{9}$ and more favorable health outcomes after treatment. ${ }^{10-12}$ On the other hand, negative outcome expectations in the acute-illness phase have been linked to a higher risk of developing chronic pain disabilities. ${ }^{13}$

Because of the strong association between positive expectancy and favorable outcomes, there is an ongoing discussion regarding the correlates of RTW expec-
Correspondence: Benjamin Claréus Department of Psychology, Lund University, Box 213, Lund 221 00, Sweden

Tel +46462228312

Fax +46 462224209

Email benjamin.clareus@psy.lu.se 
tancy. Studying these correlates may help identify factors that increase or lower expectations, and thus indirectly aid or impede rehabilitation. Sociodemographic variables, such as gender, age, and educational attainment, can influence one's recovery expectancy, ${ }^{9,11,12}$ but effects of the interaction between patients and physicians have been emphasized as well. 5,6 The effects of the patient-physician interaction may both be direct (eg, higher emotional well-being) and indirect (eg, motivation, treatment adherence), ${ }^{14}$ and their operating mechanisms have been the subject of study in several articles on recovery expectations in individuals experiencing acute and chronic pain conditions. For example, moderate-strong evidence suggests that patients' beliefs regarding their pain are often associated with those of their treating physician. ${ }^{15}$ These beliefs not only include the cause of pain and beliefs that certain behaviors might worsen it but also the prognosis for recovery. ${ }^{15,16}$ Physicians' beliefs can be conveyed by the manner in which they address and treat pain throughout several appointments, ${ }^{17}$ but it has also been shown that single consultations ${ }^{18}$ or even off-hand statements ${ }^{16}$ impact patients' prognostic expectancy. Although patients' recollection of what is said during appointments is subject to interpretative bias, Darlow et $\mathrm{al}^{16}$ argued that a focus on a physician's actual beliefs or intended messages is less informative than the patient's phenomenological experience of the interaction. In accordance with this argument, patients with subacute and chronic pain are more likely to RTW if they report that their physician recommended that they did so at any time, ${ }^{19}$ despite other findings suggesting that patients' recovery expectancy declines as a function of their current sick-leave duration. ${ }^{20}$ Studies $^{21-24}$ also suggest that patients' perceived ability to RTW increases if they have a positive perception of their physician's communicative attributes (eg, listening skills) and personal qualities (eg, respectfulness). Dibbelt et $\mathrm{al}^{25}$ even established a causal link between positive patient-physician interaction to more favorable and sustainable treatment outcomes.

Studying patients' perception of their physician's estimation of their RTW potential and other beliefs formed after consultation in samples with various pain conditions is thus important for two purposes. First, given the strong association between RTW expectancy and actual RTW, ${ }^{7,8}$ it can help identify salient predictors of RTW in future longitudinal studies focused on rehabilitation outcomes. Second, it can be utilized in developing general guidelines aiming to facilitate rehabilitation for pain patients. Such guidelines might be especially useful for physicians who work in primary care, who often manage patients with varying pain conditions ${ }^{26}$ or act as a gateway into more specialized care. ${ }^{27}$

The majority of research studying the patient-physician interaction has focused on specific clinical subpopulations, such as individuals with neck or back pain. ${ }^{13,15-19,23}$ While these kinds of homogeneous samples provide valid support for the existence of the conveyance effect in the target group, they may not adequately represent the variability of pain conditions as experienced by the general population. ${ }^{28}$ To the extent of our knowledge, two quantitative ${ }^{24,25}$ and two qualitative ${ }^{21,22}$ studies on the topic have utilized samples that included patients with many different pain conditions. These studies focused on how the physician's communicative attributes and personal qualities affected direct health outcomes, but did not address the effect of beliefs that patients formed on the basis of their physician's messages. As ability and volition are imperative factors in RTW expectancy, ${ }^{2-6}$ patients' interpretation of physicians' messages regarding their ability and volition to recover could influence their expectancy of RTW. Moreover, such pain characteristics as origin, duration, and consequent perceived disability were not accounted for in the quantitative studies, which utilized heterogeneous samples, ${ }^{24,25}$ despite the possibility of these factors having an influence on individuals' RTW expectancy.

The aim of the current study was therefore to investigate cross-sectionally the beliefs that full-time sick-listed patients have regarding their physician's opinion of their ability and volition to RTW, as well as the relationship between these beliefs and RTW expectancy. Other authors have argued that one's perceptions of one's own ability contra volition are independently associated with recovery expectancy ${ }^{4,5}$ and that patients' prognostic expectancy is directly influenced by their interpretation of physicians' messages. ${ }^{16}$ On the basis of these findings, we hypothesize that beliefs about physicians' opinions regarding ability and volition should be relatively independent constructs, such that they are weakly correlated and have differing relationships with other variables. Furthermore, these beliefs should have independent explanatory effects on RTW expectancy, even when other variables associated with RTW expectancy have been accounted for, such as sociodemographic factors, pain characteristics, and total sick-leave duration.

\section{Methods \\ Participants}

Participants were selected from a larger sample of 1,184 adults who partook in a cross-sectional online study on pain in Sweden. Data were collected between March and 
December 2017. Advertisements to partake in the study were distributed through various channels, including social media, patient societies, and billboards in health care centers. Inclusion criteria specified that participants should have been in contact with a health care provider due to their pain within the last year, that they currently received sick pay or disability benefits, or that they perceived that their level of pain had a significant impact on their quality of life. Those participants who fulfilled at least one of three inclusion criteria were briefed about the study's purpose and provided written informed consent. They subsequently answered a battery of questions, including demographic questions, pain characteristics (if their pain had been clinically diagnosed and, in if so, which diagnosis/diagnoses and their estimated pain duration), and the measures included in the current study. Participation was reimbursed with a lottery ticket.

The representativeness of the 1,184 individuals who fulfilled at least one of three inclusion criteria cannot be guaranteed, as the number of people exposed to these advertisements and who did not fulfill any inclusion criteria are unknown. However, with the exception that the sample predominantly comprised women $(75.5 \%)$, their demographics were representative of the Swedish population as a whole, eg, with regard to age, living conditions, and employment rate. ${ }^{29}$

Participants in the current study were selected from the original 1,184 respondents based on the following exclusion criteria (applied in order): those not currently on full-time sick leave ( $\mathrm{n}=873$ ), not disclosing the total duration of their sick-leave episodes $(n=51)$, or reporting that their total sickleave duration was $>10$ years $(\mathrm{n}=55)$. The first inclusion criterion was applied as we were predominantly interested in RTW expectancy among individuals who were on full-time sick leave, and expecting to RTW could be operationalized as them expecting to work more than currently within a year. The second criterion was based on previous literature where both current ${ }^{4,20}$ and total ${ }^{30}$ sick-leave duration was associated with decreases in RTW expectancy, and imputation of the missing values could thus confound results. With regard to the third criterion, post hoc examination of the data revealed that no participant who reported a total sick-leave duration $>10$ years expected to RTW within the coming year. These participants were removed, as the outcome variable of interest was expecting RTW, and our findings were consistent with the earlier RTW-expectancy decreases over time. ${ }^{4,20,30}$ However, to check that their inclusion would not appreciably change our results, we included them when checking test sensitivity.
It should be noted that we did not exclude participants based on their employment status, as current employment is not a prerequisite for sick leave in Sweden. ${ }^{31}$

\section{Measurements \\ RTW expectancy}

Expectancy of RTW was measured by a single item: "What do you think that your work situation will look like within a year?", to which participants indicated whether they believed their situation would remain unchanged $(0)$ or that they would work more (1). Previous research has shown that using a single item that defines the time frame of the desired outcome is strongly predictive of actual RTW within that period. ${ }^{8}$

\section{Pain duration}

Participants were asked to estimate in years for how long their pain had persisted from its earliest onset.

\section{Work disability}

Participants were asked to provide a general estimate of their disability to perform paid work as a result of their pain on a 1 (no disability) to 10 (full disability) scale. The phrasing of the question was adapted from the Pain Disability Index ${ }^{32}$ to focus on only paid labor, instead of both paid and unpaid labor as in the original instrument. Previous studies have confirmed sound psychometric properties of this measure. ${ }^{32,33}$

\section{Beliefs about physician's opinion}

Participants were asked to indicate how they believed that their physician evaluated their ability ("Do you believe that your physician[s] think[s] that you will recover enough to RTW?") and volition ("Do you believe that your physician[s] think[s] that you want to RTW?") to RTW on a 7-point Likert scale from $1=$ no, not at all to $7=$ yes, definitely.

\section{Statistical procedures}

For the purpose of testing if beliefs about physician's opinion were independent constructs, such that they are weakly correlated and independently associated with other variables, we computed Pearson correlation coefficients between these beliefs to each other, to perceived work disability, to pain duration, and to the total duration of their sick-leave episodes. We also postulated that not only should these beliefs be associated with RTW expectancy but that they should also have independent, significant explanatory effects on RTW expectancy when other variables associated 
with RTW expectancy had been accounted for. Therefore, we began by using Student's $t$-tests to investigate if participants expecting either working more or not working more within a year differed in work disability, pain duration, total sick-leave duration, and in their beliefs about physicians' opinions regarding their ability and volition to RTW. Effect sizes from mean-difference testing and correlations were interpreted according to Cohen's conventions: ${ }^{34}$ small (absolute $r \geq 0.1, \delta \geq 0.2$ ), medium (absolute $r \geq 0.3, \delta \geq 0.5$ ), and large (absolute $r \geq 0.5, \delta \geq 0.8$ ). Tests for independence $\left(\chi^{2}\right)$ were subsequently computed to test for group differences between participants expecting either to work more or not to work more within a year on gender, highest educational level, occupational status, and clinical diagnoses. Fisher's exact test was applied if the expected frequency in any cell was $<5$.

Finally, to test our hypothesis about beliefs having independent explanatory effects on RTW expectancy, we used hierarchical logistic regression. Beliefs about physician's opinions regarding ability and volition to RTW were added at step 1. Demographic variables (step 2) and pain characteristics (step 3) found to be independently associated with RTW expectancy were then added in subsequent steps. Two sensitivity tests of the final model were conducted: one comparing step 3 to a model with all variables, including those without significant independent relationships to RTW expectancy, and the other comparing step 3 to the similar model computed on a data set that additionally included participants who reported total sick-leave duration $>10$ years. Pooled indices for evaluating model fit included McFadden's pseudo- $R^{2},{ }^{35}$ Akaike's information criterion, ${ }^{36} \chi^{2}$-tests on differences in residual deviance, and receiver-operating characteristic curves. The contribution of independent variables was evaluated with the pooled $t$-statistic, ORs, and 95\% CIs. Analyses were carried out in R (version 3.4.1) and IBM SPSS (version 25.0.0.1).

\section{Test assumptions}

Skewness values for the continuous variables were within the common cutoff of $\pm 1,{ }^{37}$ with the exception of disability to work ( skew $=-3.42$ ). Due to the considerable skew, we replicated all analyses with the work-disability variable dichotomized as "did not indicate full disability" (score of 1-9) and "indicated full disability" (score of 10). These results did not differ significantly to those reported in the paper. Furthermore, visual inspection of the histograms additionally revealed slight deviations from normality for beliefs about physicians' opinions regarding ability and volition to
RTW. However, as the direction and effect size of all bivariate relations were similar for both parametric and nonparametric alternatives, results from Pearson's product-moment correlations are presented for the sake of interpretability. Student's independent $t$-tests were accordingly computed to test for between-group mean differences. With regard to assumptions of logistic regression, preliminary testing confirmed linearity of independent variables to $\log$ odds at all steps and weak collinearity.

\section{Attrition}

Data checks revealed that one participant had a missing value for age and 14 participants for pain duration. All correlations and t-tests were calculated by excluding those cases with missing data for the selected variables. For the logistic regression analyses, these cases were instead imputed with predictive mean matching (50 simulated data sets, 50 iterations) utilizing the Mice package (version 2.46.0) ${ }^{38}$ in $R$. Missing values in categorical variables were analyzed as separate levels and included ten participants who did not disclose their occupational status and four who did not disclose their clinical diagnosis/diagnoses.

\section{Results \\ Demographic data}

The final sample comprised 205 participants who fulfilled all three inclusion criteria. Their demographics and pain characteristics are summarized in Table 1. The majority (84\%) identified as women. The mean age was $47.24 \pm 9.66$ (range 19-66) years, average duration of pain 17.44 \pm 12.01 (range 0.05-53) years, and total duration of sick-leave episodes $3.13 \pm 2.72$ (range $0.02-10$ ) years. They reported considerable disability to perform paid work due to their pain (mean $9.3 \pm 1.8$, range $1-10$ ). Furthermore, there was considerable variation in the types of diseases reported among the $90 \%$ whose pain had been clinically diagnosed. The most common reported diagnosis was of the musculoskeletal system or connective tissue (eg, fibromyalgia, 66\%), followed by diseases of the nervous system (eg, migraine, 27\%) and injuries due to external causes (eg, whiplash, 8\%). Comorbidity was high, as $48 \%$ of the total sample reported that they had more than one clinical diagnosis.

\section{Correlations between beliefs with other variables}

Table 2 presents the bivariate relationship between beliefs about physicians' opinions on ability and volition to RTW to each other, as well as other continuous variables. Notably, 
Table I Sample demographics and pain characteristics

\begin{tabular}{|c|c|}
\hline & $\begin{array}{l}\text { n (\%)/mean } \\
\text { (SD) }\end{array}$ \\
\hline Age & $47.24(9.66)$ \\
\hline Gender & \\
\hline Women & $172(83.90)$ \\
\hline Men & $33(16.10)$ \\
\hline Educational level & \\
\hline Elementary school & $16(7.80)$ \\
\hline Upper secondary school & $111(54.15)$ \\
\hline University & $78(38.05)$ \\
\hline Occupational status & \\
\hline Employed & $180(87.80)$ \\
\hline Unemployed & $14(6.83)$ \\
\hline Student & I $(0.05)$ \\
\hline Missing data & $10(4.88)$ \\
\hline Work disability & $9.30(1.80)$ \\
\hline Pain duration (years) & $17.44(12.01)$ \\
\hline Total sick leave duration (years) & $3.13(2.72)$ \\
\hline Pain clinically diagnosed & $185(90.24)$ \\
\hline Comorbidity & \\
\hline One disclosed diagnosis & $83(40.49)$ \\
\hline Two disclosed diagnoses & $58(28.29)$ \\
\hline Three disclosed diagnoses & $23(1 \mathrm{I} .22)$ \\
\hline Four or more disclosed diagnoses & $17(8.29)$ \\
\hline Missing data & $4(1.95)$ \\
\hline Type of clinical diagnosis ${ }^{a}$ & \\
\hline $\begin{array}{l}\text { Musculoskeletal or connective tissue diseases } \\
\text { (M00-M99) }\end{array}$ & $135(65.86)$ \\
\hline Nervous system diseases (G00-G99) & $56(27.32)$ \\
\hline Injuries due to external causes (S00-T98) & $17(8.29)$ \\
\hline Diseases not elsewhere classified (R00-R99) & $16(7.80)$ \\
\hline Congenital malformations (Q00-Q99) & $13(6.34)$ \\
\hline Diseases of the genitourinary system (N00-N99) & $10(4.88)$ \\
\hline Mental and behavioral disorders (F00-F99) & $6^{\mathrm{b}}(2.93)$ \\
\hline Diseases of the digestive system (K00-K93) & $4(1.95)$ \\
\hline Diseases of the circulatory system (100-199) & $3(1.46)$ \\
\hline Neoplasms (C00-D48) & $\mathrm{I}(0.05)$ \\
\hline Metabolic diseases (E00-E90) & $\mathrm{I}(0.05)$ \\
\hline Diseases of the ear $(\mathrm{H} 00-\mathrm{H} 59)$ & $\mathrm{I}(0.05)$ \\
\hline Diseases of the respiratory system (J00-J99) & I $(0.05)$ \\
\hline Conditions associated with pregnancy (O00-O99) & I $(0.05)$ \\
\hline
\end{tabular}

Notes: $\mathrm{N}=205$. ${ }^{2}$ Categorized according to the 10th Revision of the Internationa Statistical Classification of Diseases and Related Health Problems; ball participants reported at least one comorbid somatic disease. the effect of the correlation between belief in physicians' opinions about ability and volition to RTW was small, suggesting that these variables are relatively independent and influenced by different factors. For example, total sick-leave duration was negatively correlated with belief in physicians' opinions about their ability to RTW at the medium level, but the correlation between total sick-leave duration and belief in physicians' opinions about volition to RTW was weak. Neither belief was significantly associated with work disability, but beliefs about volition were significantly associated with pain duration, whereas beliefs about ability were not.

\section{Independent associations with RTW expectancy}

Mean-difference testing between participants who expected to RTW within a year and those who did not (Table 3) showed that participants who did not expect to work more within a year were older, estimated a longer duration of pain, and that the total duration of their sick-leave episodes was longer. However, the group who expected to work more believed to a higher degree that their physician positively evaluated their ability and volition to RTW. The effect sizes of these differences were large. We found no significant difference in perceived disability to work between the two groups.

Furthermore, $\chi^{2}$-tests of independence revealed no significant association between gender $\left(\chi_{1}^{2}=1.35, P=0.25\right)$, educational level $\left(\chi_{2}^{2}=2.28, P=0.32\right)$, or occupational status $\left(\chi_{3}^{2}=1.03, P=0.79\right)$ and RTW expectancy. RTW expectancy was not significantly associated with whether the pain was diagnosed or not $\left(\chi_{1}^{2}=0.79, P=0.38\right)$ or to the number of disclosed diagnoses $\left(\chi_{3}^{2}=5.78, P=0.12\right)$. However, people who disclosed musculoskeletal or connective-tissue diseases were less likely than the rest of the sample to expect to work more within a year $\left(\chi_{1}^{2}=7.76, P=0.005\right)$, whereas those who

Table 2 Pearson's bivariate correlations between the continuous variables

\begin{tabular}{|l|l|l|l|l|l|}
\hline Variable & $\mathbf{I}^{\mathrm{a}}$ & $\mathbf{2}^{\mathrm{b}}$ & $\mathbf{3}$ & $\mathbf{4}$ & $\mathbf{5}$ \\
\hline I: Age & - & & & & \\
2: Pain duration (years) & $0.30^{\mathrm{b} * *}$ & - & & & \\
3: Sick-leave duration (years) & $0.22^{* *}$ & 0.03 & - & - & \\
4: Work disability & -0.11 & 0.02 & -0.03 & -0.06 & - \\
5: BPO: ability to RTW & $-0.22^{* *}$ & -0.08 & $-0.5 I^{* * *}$ & -0.07 & $0.23 * *$ \\
6: BPO: volition to RTW & $-0.19 * *$ & $-0.22^{* *}$ & $-0.15^{*}$ & \\
\hline
\end{tabular}

Notes: $\mathrm{N}=205$ unless otherwise specified. $* p<0.05 ; * * p<0.01 ; * * * p<0.001 ;{ }^{a} \mathrm{n}=204 ;{ }^{b} \mathrm{n}=190$.

Abbreviations: BPO, belief in physician's opinion; RTW, return to work. 
reported diseases of the genitourinary system were more likely to expect to RTW $\left(\chi_{1}^{2}=4.36, P=0.05\right)$. There was no significant association between RTW expectancy and prevalence of any other clinical disease $\left(\chi_{1}^{2}=0.14-3.38\right.$, $P=0.13-1.00)$.

\section{Dependent associations with RTW expectancy}

Those variables that were significantly associated with RTW expectancy were entered into a hierarchical regression model (Table 4). Beliefs about physicians' opinions regarding ability and volition to RTW were entered in step 1 . Total sick-leave duration and age were entered in step 2, and the presence of musculoskeletal or genitourinary system disease and pain duration in step 3. This analysis was conducted for the purpose of testing whether beliefs about physicians' opinions could influence RTW expectancy after accounting for demographic variables and pain characteristics.
Results showed that the second step explained more variance and had significantly better fit and accuracy (Figure 1) than the first step. Adding pain characteristics in step 3 did not significantly improve the model specified in step 2 .

When evaluating the contribution of individual independent variables, we found that beliefs about physicians' opinions regarding ability and volition to RTW had a small yet statistically significant effect on RTW expectancy. The size of the effect was relatively stable across all steps, such that if participants perceived that their physician had a favorable opinion regarding their ability and/or volition to RTW, they were more likely to expect a RTW within a year. Besides beliefs about physicians' opinion, only age made a significant contribution to the final model. The effect of age on RTW expectancy was such that older participants expected to RTW to a lesser degree than younger participants. Adding all possible variables (ie, work disability, gender, educational level, occupational status, whether the pain condition was

Table 3 Mean differences between participants depending on their RTW expectancy

\begin{tabular}{|c|c|c|c|c|c|c|c|}
\hline \multirow[t]{2}{*}{ Variable } & \multicolumn{2}{|c|}{$\begin{array}{l}\text { Unchanged situation } \\
\text { within a year }(n=\mid 58)\end{array}$} & \multicolumn{2}{|c|}{$\begin{array}{l}\text { Work more within a } \\
\text { year }(n=47)\end{array}$} & \multirow[t]{2}{*}{$t$} & \multirow[t]{2}{*}{$d f$} & \multirow[t]{2}{*}{$\delta$} \\
\hline & Mean & SD & Mean & SD & & & \\
\hline Age & $48.87^{a}$ & $9.29^{a}$ & 41.77 & 8.91 & $4.65 * * *$ & 202 & 0.78 \\
\hline Pain duration (years) & $18.56^{\mathrm{b}}$ & $11.80^{\mathrm{b}}$ & $13.73^{c}$ & $12.10^{c}$ & $2.37^{*}$ & 188 & 0.40 \\
\hline Total sick-leave duration (years) & 3.50 & 2.87 & 1.86 & 1.65 & $3.74 * * *$ & 203 & 0.70 \\
\hline Work disability & 9.29 & 1.87 & 9.32 & 1.56 & -0.09 & 203 & 0.02 \\
\hline BPO: ability to RTW & 2.32 & 1.73 & 4.04 & 1.77 & $-5.96 * * *$ & 203 & 0.98 \\
\hline BPO: volition to RTW & 4.69 & 2.23 & 6.15 & 1.32 & $-4.26 * * *$ & 203 & 0.80 \\
\hline
\end{tabular}

Note: ${ }^{*} P<0.05 ; * * P<0.01 ; * * * P<0.001 ;{ }^{a} n=157 ;{ }^{b} n=146 ;{ }^{c} n=44$.

Abbreviations: BPO, belief in physician's opinion; RTW, return to work.

Table 4 Hierarchical logistic regression on RTW expectancy

\begin{tabular}{|c|c|c|c|c|c|c|}
\hline \multirow[t]{2}{*}{ Independent variable } & \multicolumn{2}{|l|}{ Step I } & \multicolumn{2}{|l|}{ Step 2} & \multicolumn{2}{|l|}{ Step 3} \\
\hline & OR (95\% CI) & $\boldsymbol{t}$ & OR $(95 \% \mathrm{Cl})$ & $t$ & OR $(95 \% \mathrm{Cl})$ & $t$ \\
\hline BPO: ability to RTW & $1.55(1.28-1.88)$ & $4.48 * * *$ & $1.45(1.14-1.84)$ & $3.02 * *$ & $1.44(1.13-1.83)$ & $2.92 * *$ \\
\hline BPO: volition to RTW & $1.49(1.17-1.89)$ & $3.21 * * *$ & $1.44(1.13-1.84)$ & $2.95 * *$ & $1.42(1.11-1.83)$ & $2.74 * *$ \\
\hline Age & & & $0.94(0.90-0.98)$ & $-3.05 * *$ & $0.94(0.90-0.98)$ & $-2.75^{*}$ \\
\hline Total sick-leave duration & & & $0.92(0.75-1.13)$ & -0.78 & $0.94(0.76-1.15)$ & -0.61 \\
\hline Pain duration & & & & & $1.00(0.96-1.03)$ & -0.24 \\
\hline Musculoskeletal disease & & & & & $0.61(0.27-1.35)$ & -1.22 \\
\hline Genitourinary disease & & & & & $0.99(0.21-4.76)$ & -0.01 \\
\hline McFadden's pseudo- $R^{2}$ & 0.19 & & 0.24 & & 0.25 & \\
\hline AIC & 184.18 & & 176.59 & & 181.16 & \\
\hline Residual deviance $(d f)$ & $178.18(202)$ & & $166.59(200)$ & & $165.16(197)$ & \\
\hline$\Delta$ residual deviance & $\chi_{2}^{2}=42.56 * * *, \mathrm{a}$ & & $\chi_{2}^{2}=11.59 * *$ & & $\chi_{3}^{2}=1.43$ & \\
\hline
\end{tabular}

Notes: $\mathrm{N}=205$. OR $>$ I indicates that the independent variable was positively associated with RTW expectancy. Presence of musculoskeletal or genitourinary disease dummy coded as $0=$ no, I = yes. $* P<0.05 ; * * P<0.01$; $* * * P<0.001$; ${ }^{a}$ compared to null model.

Abbreviations: BPO, belief in physician's opinion; RTW, return to work; AIC, Akaike information criterion. 


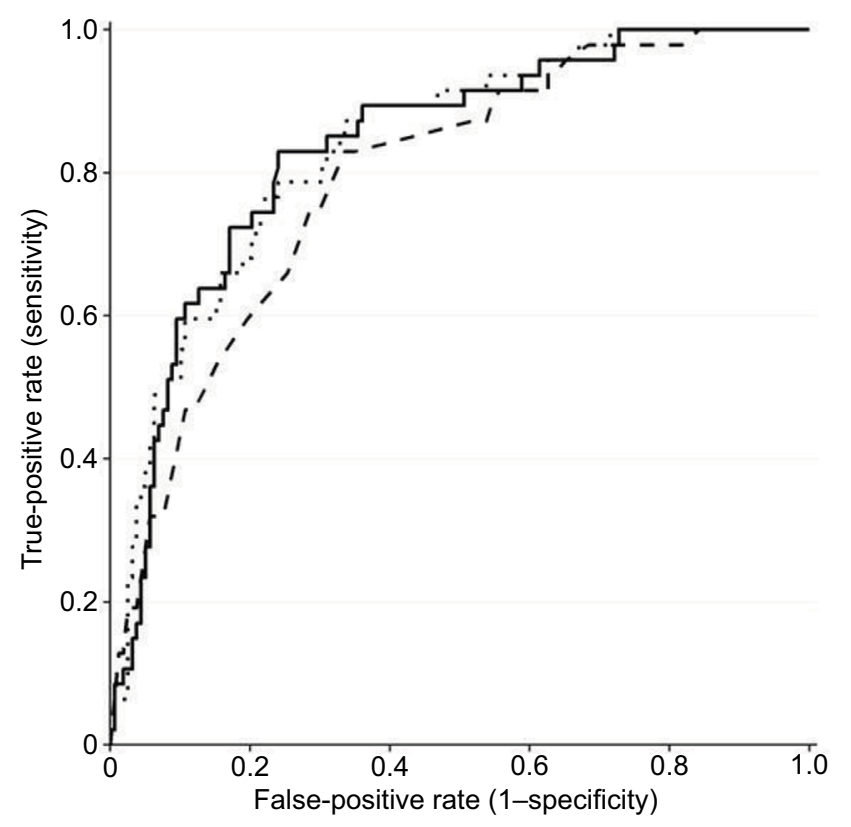

Figure I Receiver-operating characteristic curves at success rate $<0.5$ for step I (dashed), step 2 (solid), and step 3 (dotted) hierarchical logistic regression models.

diagnosed or not, number of clinical diagnoses, and the presence of specific clinical diagnoses other than musculoskeletal and genitourinary) did not appreciably change the estimates reported for step $3(\mathrm{OR}=0.01-0.07)$. When including those who reported a total duration of their sick-leave episodes $>10$ years, a slight negative direction of change was observed $(\mathrm{OR}=-0.01$ to -0.08$)$, although all variables retained significance. Due to the narrowing of the $\mathrm{CI}$, total sick-leave duration almost became significant, such that it predicted lower RTW expectancy $(\mathrm{OR}=0.89,95 \% \mathrm{CI}=0.84-0.95$; $P=0.07)$. Beliefs about physicians' opinions is thus a more salient associate of RTW expectancy in individuals who in total have been on sick leave for 10 years or less compared with those with a total sick-leave period $>10$ years.

\section{Discussion}

In the current study, we hypothesized that beliefs held by fulltime sick-listed individuals about their physician's opinion regarding their ability (ie, "can do") and volition (ie, "wanting to do") to RTW should be relatively independent constructs and have an explanatory effect on RTW expectancy even when accounting for other variables. Results supported our hypotheses, such that a positive RTW expectancy within a year among participants whose total sick-leave duration was $<10$ years was significantly influenced by favorable beliefs about their physician's opinion regarding their ability and volition to RTW. The effect was stable and significant, even when controlling for various sociodemographic factors and pain characteristics.

Patients' prognostic expectancy for RTW is thus influenced directly by their interpretation about physicians' messages regarding their ability and volition to RTW. Our findings agree with earlier qualitative work, suggesting that these interpretations may result in enduring impacts on recovery expectancy in individuals with low-back pain. ${ }^{16}$ Moreover, other authors ${ }^{15}$ have found quantitative support for patients being affected by physicians' beliefs regarding the cause of pain and the behaviors that worsen it, and our study shows that other beliefs formed of physicians' messages about ability and volition might be another factor affecting rehabilitation. Beliefs in physicians' opinions about ability and volition were also only weakly correlated, and independently related to other variables, including RTW expectancy. This is in line with previous literature, which describes ability and volition as separate factors, ${ }^{4,6}$ both contributing differently to the RTW process. ${ }^{5}$ In practice, however, physical therapists describe the empowerment of ability as more pertinent than volition for rehabilitation purposes. ${ }^{23}$ Our finding that beliefs about physicians' opinions regarding ability and volition contribute equally to RTW expectancy suggests that health care professionals managing patients with pain should encourage or affirm volition as well. This might be especially important for patients whose current sick-leave episode has exceeded 2 months, as many of these patients are uncertain of whether they want to RTW or not. ${ }^{4}$ However, we also found that the association of these beliefs to RTW expectancy decreased when participants had total sick leave $>10$ years, indicating that interventions other than encouragement of ability and volition might be more suitable for increasing RTW expectancy in these individuals.

Previous research has associated advanced age with a general decrease in RTW rates, ${ }^{7,30}$ and in our study age made a significant contribution to RTW expectancy when other factors were controlled for. Lower RTW expectancy among older participants in our study could be explained by imminent retirement or beliefs that restricting pain is inevitable. ${ }^{39}$ On the other hand, the insignificant association between total sick-leave duration and RTW expectancy highlights the importance of physicians conveying a positive message regarding patients' ability and volition to RTW, especially if the amassed sick-leave duration is 10 years or less. However, such might not be the case in practice, as we also found that total sick-leave duration was negatively correlated with favorable beliefs about physicians' opinions regarding ability to RTW. These decreases might be attributed to repeated 
sick-leave episodes negatively influencing patients' perceptions of physicians' messages or physicians being more pessimistic regarding these patients' ability to RTW. Other authors have accordingly shown that RTW expectancy declines as a function of the current sick-leave duration ${ }^{4,20}$ and that actual RTW is lower in currently sick-listed individuals with longer extent of previous sick-leave. ${ }^{30}$

Although coprevalence of chronic pain conditions is common, this is seldom accounted for in pain research. ${ }^{28}$ We addressed this issue by recruiting our sample from a community population with large variability in regard to pain characteristics, rather than focusing on a specific clinical subpopulation. However, we did not find any significant association between the prevalence of multiple pain diagnoses and RTW expectancy. This was also the case with undiagnosed pain conditions, which contrasts with qualitative findings suggesting that a diagnosis can be perceived as reassuring by patients in rehabilitation. ${ }^{40}$ Moreover, significant associations between specific pain disorders and pain duration with RTW expectancy were not significant when beliefs regarding physicians' opinions and sociodemographic factors were controlled for. Therefore, we suggest that while the origin and duration of pain might be associated with RTW expectancy, other factors make a more significant contribution.

\section{Limitations and future research}

A few limitations of the present study are notable. First, we did not measure the treating physicians' actual beliefs, but rather patients' aggravated interpretation of what had been said to them in consultation and treatment. As such, it is not possible from our study to say anything about how physicians' beliefs affect patients' RTW expectancy, nor which specific messages these beliefs are based upon. Other studies have suggested that it is the aggregated effect of the communication over time that influences patients, rather than what is actually said or intended to be conveyed in consultation. ${ }^{14,16}$ Patients' perceived beliefs might thus be more important for RTW than physicians' actual beliefs, as the correlation between a patient's RTW expectancy and that of their physician is small. ${ }^{13}$ As RTW expectancy is strongly predictive of actual RTW, ${ }^{7,8}$ our study suggests patients' beliefs regarding physicians' opinions about ability and volition to RTW might be especially useful predictors of RTW in future longitudinal research on rehabilitation outcomes. Prospective research testing both patients' and physicians' beliefs is however needed to confirm this hypothesis, as the current study was conducted cross-sectionally and thus cannot account for RTW rates. Moreover, the direction of association assumed in the current study was based only on theoretical accounts, suggesting that evaluation of ability and volition to RTW amasses patients' RTW expectancy ${ }^{2,4,5}$ and that knowledge of physician prognosis precede the formation of one's recovery expectancy. ${ }^{16}$ Longitudinal research is however needed to establish causality between these beliefs and RTW expectancy.

Furthermore, our sample reported considerable disability to work, which might have confounded the effect sizes. Higher pain disability has in previous studies been associated with lower internalization of messages from physicians and overall negative recovery expectancy. ${ }^{41}$ This implies that beliefs about physicians' opinions could have a larger impact in samples with lower pain disability. With regard to other pain characteristics, such as duration or diagnosis, our study relied on self-report. This means that participants might have overestimated the duration of their pain or reported diagnoses that had not been clinically confirmed. There are examples of previous studies that have successfully utilized self-estimates of pain duration, ${ }^{42,43}$ but future research could consult clinical records to confirm participants' diagnoses. Moreover, clinical records would make it possible to control only for current sick-leave duration, as both current and previous extent of sick-leave was measured in this study.

Finally, while our results are (due to the nature of our sample) generalizable to individuals who experience pain and have been on sick-leave for a total of 10 years or less, research on homogeneous samples with regard to the origin of pain is necessary to provide valid support of the effect among specific subpopulations (eg, patients with only musculoskeletal or neuropathic pain). Furthermore, cohort studies are necessary to study the effect in larger populations, as our recruitment strategy primarily targeted individuals who sought social support with regard to their pain by joining patient societies or social media fora. Moreover, our sample was imbalanced in terms of gender (83.9\% women). This imbalance could explain why we did not manage to replicate previous studies that demonstrated a significant effect of participant gender on outcome expectancy. ${ }^{9,11,12}$ Further studies utilizing cohorts and accounting for participants' gender in the analysis are thus necessary.

\section{Conclusion}

The current study found that the beliefs that individuals with total sick leave $\leq 10$ years have about their physician's opinion regarding their ability and volition to RTW influence their RTW expectancy, even when sociodemographic 
factors and pain characteristics are controlled for. Given the strong association between RTW expectancy and actual RTW, these beliefs could influence the outcome of rehabilitation. Therefore, we recommend that patients' ability and volition to RTW should be explicitly addressed by physicians, as well as encouraged or affirmed when appropriate. Future studies should be aimed toward investigating the longitudinal influence of these beliefs on actual RTW rates.

\section{Ethics statement}

The current study was conducted in accordance with the principles of the Declaration of Helsinki and was approved by the Regional Ethics Board at the University of Gothenburg (1120-16).

\section{Acknowledgments}

This work was supported by AFA Insurance (grant 140379). AFA Insurance had no role in study design, collection, analysis, or interpretation of data, writing the manuscript, or the decision to submit the paper for publication.

\section{Disclosure}

The authors report no conflicts of interest in this work.

\section{References}

1. Thompson AG, Suñol R. Expectations as determinants of patient satisfaction: concepts, theory and evidence. Int J Qual Health Care. 1995;7(2):127-141.

2. Bialosky JE, Bishop MD, Cleland JA. Individual expectation: an overlooked, but pertinent, factor in the treatment of individuals experiencing musculoskeletal pain. Phys Ther. 2010;90(9):1345-1355.

3. Flood AB, Lorence DP, Ding J, McPherson K, Black NA. The role of expectations in patients' reports of post-operative outcomes and improvement following therapy. Med Care. 1993;31(11):1043-1056.

4. Berglind H, Gerner U. Motivation and return to work among the long-term sicklisted: an action theory perspective. Disabil Rehabil. 2002;24(14):719-726.

5. Franche RL, Krause N. Readiness for return to work following injury or illness: conceptualizing the interpersonal impact of health care, workplace, and insurance factors. J Occup Rehabil. 2002;12(4):233-256.

6. Darlow B. Beliefs about back pain: the confluence of client, clinician and community. Int J Osteopath Med. 2016;20:53-61.

7. Heijbel B, Josephson M, Jensen I, Stark S, Vingård E. Return to work expectation predicts work in chronic musculoskeletal and behavioral health disorders: prospective study with clinical implications. J Occup Rehabil. 2006;16(2):169-180.

8. Iles RA, Davidson M, Taylor NF, O'Halloran P. Systematic review of the ability of recovery expectations to predict outcomes in non-chronic non-specific low back pain. J Occup Rehabil. 2009;19(1):25-40.

9. Ozegovic D, Carroll LJ, David Cassidy J. Does expecting mean achieving? The association between expecting to return to work and recovery in whiplash associated disorders: a population-based prospective cohort study. Eur Spine J. 2009;18(6):893-899.

10. Mondloch MV, Cole DC, Frank JW. Does how you do depend on how you think you'll do? A systematic review of the evidence for a relation between patients' recovery expectations and health outcomes. Can Med Assoc J. 2001;165(2):174-179.
11. Goldstein MS, Morgenstern H, Hurwitz EL, Yu F. The impact of treatment confidence on pain and related disability among patients with low-back pain: results from the University of California, Los Angeles, low-back pain study. Spine J. 2002;2(6):391-399.

12. Gepstein R, Arinzon Z, Adunsky A, Folman Y. Decompression surgery for lumbar spinal stenosis in the elderly: preoperative expectations and postoperative satisfaction. Spinal Cord. 2006;44(7):427-431.

13. Kapoor S, Shaw WS, Pransky G, Patterson W. Initial patient and clinician expectations of return to work after acute onset of work-related low back pain. J Occup Environ Med. 2006;48(11):1173-1180.

14. Street RL, Makoul G, Arora NK, Epstein RM. How does communication heal? Pathways linking clinician-patient communication to health outcomes. Patient Educ Couns. 2009;74(3):295-301.

15. Darlow B, Fullen BM, Dean S, Hurley DA, Baxter GD, Dowell A. The association between health care professional attitudes and beliefs and the attitudes and beliefs, clinical management, and outcomes of patients with low back pain: a systematic review. Eur J Pain. 2012;16(1):3-17.

16. Darlow B, Dowell A, Baxter GD, Mathieson F, Perry M, Dean S. The enduring impact of what clinicians say to people with low back pain. Ann Fam Med. 2013;11(6):527-534.

17. Daykin AR, Richardson B. Physiotherapists' pain beliefs and their influence on the management of patients with chronic low back pain. Spine. 2004;29(7):783-795.

18. Skatteboe S, Røe C, Fagerland MW, Granan LP. Expectations of pain and functioning in patients with musculoskeletal disorders: a crosssectional study. BMC Musculoskelet Disord. 2017;18(48):1-9.

19. Dasinger LK, Krause N, Thompson PJ, Brand RJ, Rudolph L. Doctor proactive communication, return to work recommendation, and duration of disability after a workers' compensation low back injury. J Occup Environ Med. 2001;43(6):515-525.

20. Carstens JK, Shaw WS, Boersma K, Reme SE, Pransky G, Linton SJ. When the wind goes out of the sail - declining recovery expectations in the first weeks of back pain. Eur J Pain. 2014;18(2):269-278.

21. Mussener U, Svensson T, Soderberg E, Alexanderson K. Encouraging encounters: Sick-listed persons' experiences of interactions with rehabilitation professionals. Soc Work Health Care. 2007;46(2): 71-87.

22. Sturesson M, Edlund C, Falkdal AH, Bernspång B. Healthcare encounters and return to work: a qualitative study on sick-listed patients' experiences. Prim Health Care Res Dev. 2014;15(4):464-475.

23. Jeffrey JE, Foster NE. A qualitative investigation of physical therapists' experiences and feelings of managing patients with nonspecific low back pain. Phys Ther. 2012;92(2):266-278.

24. Lynöe N, Wessel M, Olsson D, Alexanderson K, Helgesson G. Respectful encounters and return to work: empirical study of long-term sick-listed patients' experiences of Swedish healthcare. BMJ Open. 2011;1(2):e00246.

25. Dibbelt S, Schaidhammer M, Fleischer C, Greitemann B. Patient-doctor interaction in rehabilitation: the relationship between perceived interaction quality and long-term treatment results. Patient Educ Couns. 2009;76(3):328-335.

26. Fink P, Rosendal M. Recent developments in the understanding and management of functional somatic symptoms in primary care. Curr Opin Psychiatry. 2008;21(2):182-188.

27. Starfield B. Is primary care essential? Lancet. 1994;344(8930): 1129-1133.

28. Maixner W, Fillingim RB, Williams DA, Smith SB, Slade GD. Overlapping chronic pain conditions: Implications for diagnosis and classification. J Pain. 2016;17(9 Suppl):T93-T107.

29. Claréus B, Bäck EA. An investigation of physical pain among Swedish community adults: Sample demographics and pain characteristics. Lund Psychological Reports. 2018;18(1):1-15.

30. von Celsing A-S, Svärdsudd K, Eriksson H-G, Björkegren K, Eriksson M, Wallman T. Determinants for return to work among sickness certified patients in general practice. BMC Public Health. 2012;12:1077. 
31. Försäkringskassan [webpage on the Internet]. Sjukpenning för arbetssökande [Sickness benefit for employees]. Försäkringskassan [Swedish Social Insurance Agency]. Available from: https://www.forsakringskassan.se/privatpers/sjuk/arbetssokande/sjukpenning. Accessed October 18, 2018.

32. Tait RC, Chibnall JT, Krause S. The pain disability index: psychometric properties. Pain. 1990;40(2):171-182.

33. Pollard CA. Preliminary validity study of the pain disability index. Percept Mot Skills. 1984;59(3):974.

34. Cohen J. A power primer. Psychol Bull. 1992;112(1):155-159.

35. McFadden D. Conditional logit analysis of qualitative choice behavior. In: Zarembka P, editor. Frontiers in Econometrics. New York: Wiley; 1973:105-142.

36. Akaike H. A new look at the statistical model identification. IEEE Trans Automat Contr. 1974;19(6):716-723.

37. Hair JF, Tatham RL, Anderson RE, Black W. Multivariate Data Analysis. London: Prentice Hall; 1998.
38. Buuren SV, Groothuis-Oudshoorn K. mice: Multivariate imputation by chained equations in R. J Stat Softw. 2010;45(3).

39. Makris UE, Higashi RT, Marks EG, et al. Ageism, negative attitudes, and competing co-morbidities - why older adults may not seek care for restricting back pain: a qualitative study. BMC Geriatr. 2015;15:39.

40. Darlow B, Dean S, Perry M, Mathieson F, Baxter GD, Dowell A. Acute low back pain management in general practice: uncertainty and conflicting certainties. Fam Pract. 2014;31(6):723-732.

41. Briggs AM, Jordan JE, Buchbinder R, et al. Health literacy and beliefs among a community cohort with and without chronic low back pain. Pain. 2010;150(2):275-283.

42. Chibnall JT, Tait RC. The pain disability index: factor structure and normative data. Arch Phys Med Rehabil. 1994;75(10):1082-1086.

43. Cano A. Pain catastrophizing and social support in married individuals with chronic pain: the moderating role of pain duration. Pain. 2004;110(3):656-664.

\section{Publish your work in this journal}

The Journal of Pain Research is an international, peer reviewed, open access, online journal that welcomes laboratory and clinical findings in the fields of pain research and the prevention and management of pain. Original research, reviews, symposium reports, hypothesis formation and commentaries are all considered for publication.

\section{Dovepress}

The manuscript management system is completely online and includes a very quick and fair peer-review system, which is all easy to use. Visit http://www.dovepress.com/testimonials.php to read real quotes from published authors. 